\title{
COUETTE FLOW PROBLEM FOR AN UNSTEADY MHD THIRD-GRADE FLUID WITH HALL CURRENTS
}

\author{
MOHAMMAD AZRAM ${ }^{1}$ AND HAIDER ZAMAN ${ }^{2}$ \\ ${ }^{1}$ Department of Science in Engineering, \\ Faculty of Engineering, International Islamic University Malaysia, \\ PO Box 10, 50728, Kuala Lumpur, Malaysia. \\ ${ }^{2}$ Faculty of Numerical Sciences, Islamia College University 25120, \\ Peshawar 25000, Pakistan.
}

azram50@hotmail.com

\begin{abstract}
In this work, we analyze Couette flow problem for an unsteady mangnetohydrodynamic (MHD) third-grade fluid in the presence of a pressure gradient and Hall currents. Existing literature on the topic shows that the effecs of Hall current on Couette flow of an unsteady MHD third-grade fluid with a pressure gradient has not yet been investigated. The arising non-linear problem is solved by the homotopy analysis method (HAM) and the convergence of the obtained complex series solution is carefully analyzed. The effects of pressure number, Hartmann number and Hall parameter on unsteady velocity are discussed via analysis of plots.
\end{abstract}

ABSTRAK: Kajian dijalan untuk menganalisa masalah aliran Couette bagi bendalir MHD gred ketiga dan arus Hall. Bagi topik ini kesan arus Hall terhadap aliran Couette dalam bendalir MHD gred ketiga tak mantap dengan kecerunan tekanan, belum pernah dikaji selidik. Masalah tak linear berbangkit diselesaikan dengan kaedah analisis homotopi (HAM) dan ketumpuan solusi rangkaian kompleks dianalisa dengan teliti. Kesan nilai tekanan, nombor Hartmann dan parameter Hall terhadap halaju tak mantap diperbincangkan melalui plot yang dianalisis.

KEYWORDS: Couette flow; hall currents; unsteady flow; third-grade fluid; HAM

\section{INTRODUCTION}

In fluid mechanics, everyone is familiar with the Couette flow problem, the flow between two parallel plates in which bottom plate is fixed and upper plate is initially at rest and is suddenly set into motion in its own plane with a constant velocity, is termed as Couette flow [1,2]. Bhaskara and Bathaiah [3] have analyzed the Couette flow problem with Hall effects for flow through a porous straight channel. Ganapathy [4] has written a note on the oscillatory Couette flow in a rotating system. Erdogan [5] solved unsteady Couette flow for viscous fluid by the Laplace transform method. Stokes and Couette flows due to an oscillating wall have been discussed by Khaled and Vafai [6]. Hayat et al. [7] used the Laplace transform method to determine the analytic solutions of Couette flows of a second grade fluid. Oscillatory Couette flow has been studied by Singh [8]. Guria [9] discussed the Couette flow problem for rotating and oscillatory flow. Couette flow of an unsteady third-grade fluid with variable magnetic field has been investigated by Hayat and Kara [10], where the fluid is in an annular region between two coaxial cylinders. The axial Couette flow problem of an electrically conducting fluid in an annulus has been examined by Hayat et al. [11]. Das et al. [12] studied unsteady Couette flow problem in a rotating system. Recently, Zaman et al. [13] presented a solution for unsteady Couette flow 
problem for the Eyring-Powell model. When a strong magnetic field is applied in an ionized gas of low density, the conductivity normal to the magnetic field is decreased by free spiraling of electrons and ions about the magnetic lines of force before suffering collisions. This phenomenon is known as the Hall effect and a current induced in a direction normal to the electric and magnetic fields is called the Hall current [14]. The study of the effects of Hall currents on flow of non-Newtonian fluids [15-23] is important because of its applications in power generators and pumps, Hall accelerators, refrigeration coils, electric transformers, in flight MHD, electronic system cooling, cool combustors, fiber and granular insulation, oil extraction, thermal energy storage, and flow through filtering devices.

In order to understand the interaction of electric, magnetic, and hydrodynamic forces in the unsteady third-grade fluid, we considered a simple flow problem, known as the Couette flow. The effects of a pressure gradient and Hall current on the flow are also taken in to account. The complex analytical solution for the non-linear problem is found by using the homotopy analysis method (HAM) [24- 31].

This solution is valid for all values of time in the whole spatial domain $0 \leq \eta<1$. The convergence of the analytic solution is ensured with the help of the $\hbar$-curve. The effect of pressure number, Hartmann number, Hall parameter, second-grade parameter and thirdgrade parameters on the unsteady velocity are illustrated through plots. Also, the effects of the pertinent parameters on the local skin friction co-efficient at the surface of the wall are presented numerically in tabular form.

\section{FORMULATION OF THE PROBLEM AND ITS ANALYTIC SOLUTION}

Consider the unsteady flow of an electrically conducting incompressible third-grade fluid between two parallel flat plates, subjected to a uniform transverse magnetic field. We assume that the bottom plate is fixed and the top plate is stationary when $t<0$ and at $t=0$, the top plate starts moving impulsively in its own plane with a constant velocity $U$ and a pressure gradient is also applied. The flow here is maintained by the motion of the top plate. The Cauchy stress tensor $T$ for a third-grade fluid is given as [32]

$$
T=-p I+\mu A_{1}+\alpha_{1} A_{2}+\alpha_{2} A_{1}^{2}+\beta_{1} A_{3}+\beta_{2}\left(A_{1} A_{2}+A_{2} A_{1}\right)+\beta_{3}\left(t r A_{1}^{2}\right) A_{1}
$$

where $p$ is the scalar pressure, $I$ is the identity tensor, $\mu$ is the co-efficient of viscosity $\alpha_{i}, \beta_{j},(i=1,2$ and $j=1,2,3)$ are the material parameters of third-grade fluid, and $A_{i}(i$ $=1,2,3)$ are the first three Rivlin-Ericksen tensors defined by [32]

$$
\begin{aligned}
& A_{1}=(\operatorname{grad} V)+(\operatorname{grad} V)^{T} \\
& A_{n+1}=\frac{d A_{n}}{d t}+A_{n}(\operatorname{grad} V)+(\operatorname{grad} V)^{T} A_{n}, n=1,2 .
\end{aligned}
$$

The equations governing the magneto-hydrodynamic flow with Hall effects are:

$$
\text { Velocity Field: } \quad V=[u(y ; t), 0,0]
$$


Continuity equation: $\quad \operatorname{div} V=0$

Equation of motion:

$$
\rho \frac{d V}{d t}=\operatorname{div}(T)+(J \times B)
$$

Maxwell equations:

$$
\operatorname{div}(B)=0, \operatorname{curl}(B)=\mu_{m} J, \operatorname{curl}(E)=-\frac{\partial B}{\partial t}
$$

Generalized Ohm's law:

$$
J+\frac{w_{e} \tau_{e}}{B_{o}} J \times B=\sigma(E+V \times B)
$$

Where $u(y ; t)$ is the velocity component in the $x$-direction, $t$ is time, $B\left(=B_{0}+b\right)$ is the total magnetic field, $B_{0}$ is the applied magnetic field, $b$ is the induced magnetic field, $J$ is the current density, $\sigma$ is the electrical conductivity of the fluid, $E$ is the electric field, $\mu \mathrm{m}$ is the magnetic permeability, $\rho$ is the fluid density, $w_{e}$ and $\tau_{e}$ are the cyclotron frequency and collision time of the electrons respectively. We assume that, the quantities $\rho, \mu_{m}$ and $\sigma$ are constants throughout the flow field, the magnetic field $B$ is normal to the velocity vector $V$ and the induced magnetic field is neglected compared with the imposed magnetic field, so that the magnetic Reynolds number is small [33]. We also suppose that $w_{e} \tau_{e} \sim \mathrm{O}$ (1) and $w_{i} \tau_{i} \ll<1$ (where $w_{i}$ and $\tau_{i}$ are the cyclotron frequency and collision time for ions respectively). Continuity Eqn. (5) is identically satisfied by the velocity taken in Eqn. (4). Under the aforementioned assumptions the unsteady Couette flow problem with Hall currents become;

$$
\begin{aligned}
\frac{\partial u}{\partial t}= & -\frac{1}{\rho} \frac{\partial p}{\partial x}+v \frac{\partial^{2} u}{\partial y^{2}}-\frac{\sigma B_{0}^{2}(1+i \epsilon)}{\rho\left(1+\epsilon^{2}\right)} u+\frac{\alpha_{1}}{\rho} \frac{\partial^{3} u}{\partial y^{2} \partial t} \\
& +\frac{\beta_{1}}{\rho} \frac{\partial^{4} u}{\partial y^{2} \partial t^{2}}+\frac{6\left(\beta_{2}+\beta_{3}\right)}{\rho}\left(\frac{\partial u}{\partial y}\right)^{2} \frac{\partial^{2} u}{\partial y^{2}} \\
0=- & \frac{1}{\rho} \frac{\partial p}{\partial y}
\end{aligned}
$$

The boundary and initial conditions are

$$
\begin{array}{lll}
u(y, t)=0, & \text { at } y=0, & \text { for } t>0, \\
u(y, t)=u_{w}=U, & \text { at } y=h, & \text { for } t \geq 0, \\
u(y, t)=0, & \text { at } t=0, & \text { for } 0 \leq y<h
\end{array}
$$

where $v$ is the kinematic viscosity, $\in\left(=w_{e} \tau_{e}\right)$ is the Hall parameter, $U$ is the velocity of the upper plate and $h$ is the distance between two parallel plates and it will be considered as a length scale of the flow, eqn. (10) shows that $p$ is independent of $y$. In order to non-dimensionalize the problem let us introduce the similarity transformations,

$$
u=U f(\eta, \xi), \eta=\frac{y}{h}, \xi=\frac{v t}{h^{2}},
$$

where $f(\eta, \xi)$ is the dimensionless velocity function, $\eta$ is the dimensionless distance from the bottom wall and $\xi$ is the dimensionless time. Eqn. (9) and eqn. (11) become

$$
\begin{aligned}
& f^{\prime \prime}+\alpha \frac{\partial f^{\prime \prime}}{\partial \xi}+\beta \frac{\partial^{2} f^{\prime \prime}}{\partial \xi^{2}}-\frac{\mathrm{N}(1+i \in)}{\left(1+\epsilon^{2}\right)} f+\varsigma f^{\prime 2} f^{\prime \prime}-\frac{\partial f}{\partial \xi}-P=0 \\
& f(0, \xi)=0, f(1, \xi)=1, \text { for } \xi>0,
\end{aligned}
$$




$$
f(\eta, 0)=0, \text { for } 0 \leq \eta<1 \text {, }
$$

where prime denotes differentiation with respect to $\eta, \alpha\left(=\alpha_{1} / \rho h^{2}\right)$ is dimensionless second-grade parameter, $\beta\left(=\beta_{1} v / \rho h^{4}\right), \varsigma\left(=\frac{6\left(\beta_{2}+\beta_{3}\right) U^{2}}{\rho v h^{2}}\right)$ are dimensionless third-grade fluid material parameters, $P\left(=\frac{h^{2}}{\rho U v} \frac{d p}{d x}\right)$ is the dimensionless pressure number and $N(=$ $\left.\sigma B_{0}^{2} h^{2} / \rho v\right)$ is the dimensionless modified Hartmann number [33]. The local skin friction coefficient or fractional drag coefficient on the surface of the moving wall is

$$
C_{f}=\frac{\left.2 \tau_{x y}\right|_{y=h}}{\rho u_{w}^{2}}
$$

Now using equations (1), (2), (3), (4) and (12) the eqn. (15) can be written in dimensionless variables as

$$
R_{e} \times C_{f}=2\left\{f^{\prime}(1, \xi)+\alpha \frac{\partial}{\partial \xi} f^{\prime}(1, \xi)+\beta \frac{\partial^{2} f^{\prime}(1, \xi)}{\partial \xi^{2}}+\frac{1}{3} \varsigma\left(f^{\prime}(1, \xi)\right)^{3}\right\}
$$

where $R_{e}(=U h / v)$ is the Reynolds number. The boundary conditions (14) lead us to take base functions for velocity $f(\eta, \xi)$ as

$$
\left\{\eta^{n} \xi^{j} /, n \geq 0, j \geq 0\right\}
$$

The velocity $f(\eta, \xi)$ can be expressed in terms of base functions as

$$
f(\eta, \xi)=\sum_{n=0}^{\infty} \sum_{j=0}^{\infty} \Omega_{n}^{j} \eta^{n} \xi^{j}
$$

To start with the homotopy analysis methods, due to the boundary conditions (14) it is reasonable to choose the initial guess approximation

$$
f_{0}(\eta, \xi)=\eta(1+\xi-\eta \xi), \xi>0
$$

and the auxiliary linear operator

$$
\mathcal{L}(f)=\frac{\partial^{3} f(\eta, \xi)}{\partial \eta^{3}}
$$

Following the HAM and trying higher iterations with the unique and proper assignment of the results converge to the exact solution:

$$
f(\eta, \xi) \approx f_{0}(\eta, \xi)+f_{1}(\eta, \xi)+f_{1}(\eta, \xi)+f_{2}(\eta, \xi)+\cdots+f_{m}(\eta, \xi)
$$

At $\in=0.1, N=0.1, \alpha=0.1, \beta=0.1, \varsigma=0.1, P=0.1$ using the symbolic computation we obtained

$$
\begin{aligned}
f_{1}(\eta, \xi)= & \eta(1+\xi-\eta \xi)+\frac{3 \hbar \eta \xi}{10}-\frac{3 \hbar \eta^{2} \xi}{10} \\
& -\frac{\hbar \eta \xi^{2}}{15}-\frac{\hbar \eta^{2} \xi^{2}}{10}+\frac{\hbar \eta^{3} \xi^{2}}{6}+\frac{13 \hbar \eta \xi^{3}}{15}-\frac{11 \hbar \eta^{3}}{10} \\
& +\frac{3 \hbar \eta^{3} \xi^{3}}{10}-\frac{\hbar \eta^{4} \xi^{3}}{15}+\left(\frac{227}{1515}+\frac{i}{606}\right) \hbar \eta \xi^{4}-\frac{\hbar \eta^{2} \xi^{4}}{20}
\end{aligned}
$$




$$
\begin{aligned}
& -\left(\frac{5}{303}+\frac{i}{606}\right) \hbar \eta^{3} \xi^{4}-\frac{\hbar \eta^{4} \xi^{4}}{12}+\left(\frac{5}{606}+\frac{i}{1212}\right) \hbar \eta \xi^{5} \\
& -\left(\frac{5}{303}+\frac{i}{606}\right) \hbar \eta^{3} \xi^{5}+\left(\frac{5}{606}+\frac{i}{1212}\right) \hbar \eta^{4} \xi^{5}
\end{aligned}
$$

Similarly $f_{2}(\eta, \xi), f_{3}(\eta, \xi), f_{4}(\eta, \xi)$ and so on are calculated. The obtained values of $f_{0}, f_{1}, f_{2},-----$ lead us to take

$$
f_{m}(\eta, \xi)=\sum_{n=0}^{2 m+2} \sum_{j=0}^{3 m+3-n} \Omega_{m, n}^{j} \eta^{n} \xi^{j}
$$

The total complex analytic solution in compact form is as

$$
f(\eta, \xi)=\sum_{m=0}^{\infty} f_{m}(\eta, \xi)=\lim _{M \rightarrow \infty}\left(\sum_{m=0}^{M} \sum_{j=0}^{3 m+3} \Omega_{m, 0}^{j} \eta^{n} \xi^{j}\right)
$$

where from initial guess in eqn. (19) we obtain

$$
\begin{aligned}
& \Omega_{0,1}^{0}=1, \Omega_{0,1}^{1}=1, \Omega_{0,2}^{1}=-1 \\
& \Omega_{0, n}^{j}=0, \quad(j=0,1,2,3), \quad(n=0,1,2)
\end{aligned}
$$

all other unknown constants can be determined by utilizing eqn. (25) and using the recurrence relations, which we have calculated but it is not possible to write here due to their length. We know that the auxiliary parameter $\hbar$ gives the convergence region and rate of approximation for the homotopy analysis method. From $\hbar$-curve in Fig. 1 we note that the range for the admissible value for $\hbar$ is $-1.5<\hbar<0$. Our calculations depict that the series of the dimensionless velocity in eqn. (25) converges in the whole region of $\eta$ and $\xi$ for $\hbar=-0.5$.

\section{GRAPHS, TABLES AND DISCUSSION}

The discussion of emerging parameters on the dimensionless velocity $f(\eta, \xi)$ is as follows:

Figures 2 to 7 are plotted in the absence of Hall currents and in Fig. 8 the Hall current is taken into account.

Figure 2 presents the velocity profile $f$ for various values of $\xi$. This figure shows that with the passage of time the velocity of the fluid increases due to continuous motion of the upper plate. The boundary layer thickness decreases with the passage of time and shear thinning is seen. Figure 3 elucidates the variation of Hartmann number on the velocity. It is found that the velocity increases with an increase in $N$ and the boundary layer thickness decreases. This means that the magnetic force provides a mechanism to the control of boundary layer thickness. Figure 4 illustrates the influence of a second-grade parameter on the velocity profile $f$. It is evident from the figure that an increase in $\alpha$ results in the decrease of the velocity; here boundary layer thickness increases and shear thickening is observed. 


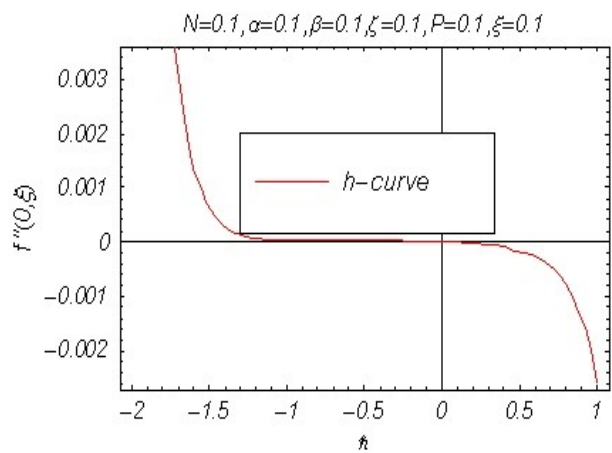

Fig.1: $\hbar$-curve for $f(\eta, \xi)$.

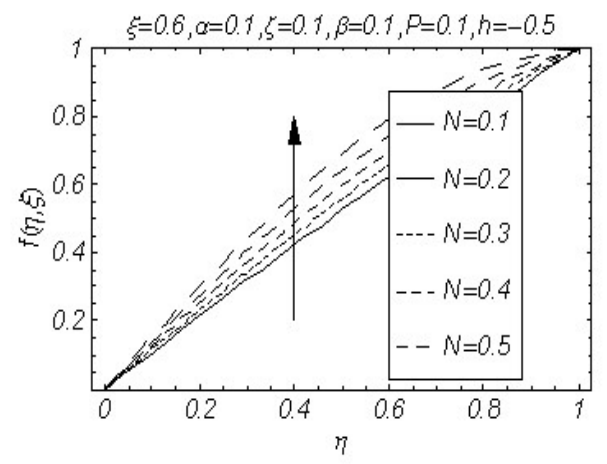

Fig. 3: Influence of $N$ on $f(\eta, \xi)$.

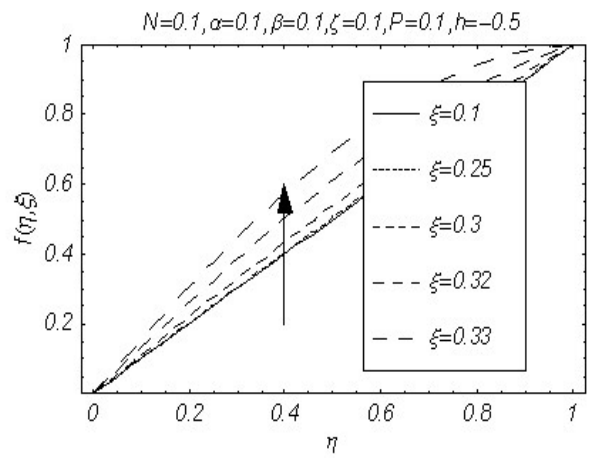

Fig. 2: Influence of $\xi$ on $f(\eta, \xi)$.

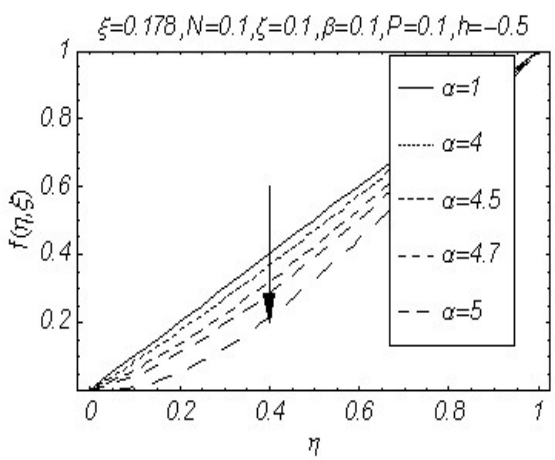

Fig. 4: Influence of $\alpha$ on $f(\eta, \xi)$.

In Fig. 5 and Fig. 6 the velocity distribution is presented for the various values of third-grade parameters $\beta$ and $\zeta$. It is observed that the velocity increases by increasing the influence of $\beta$ and decreases by increasing the influence of $\zeta$.

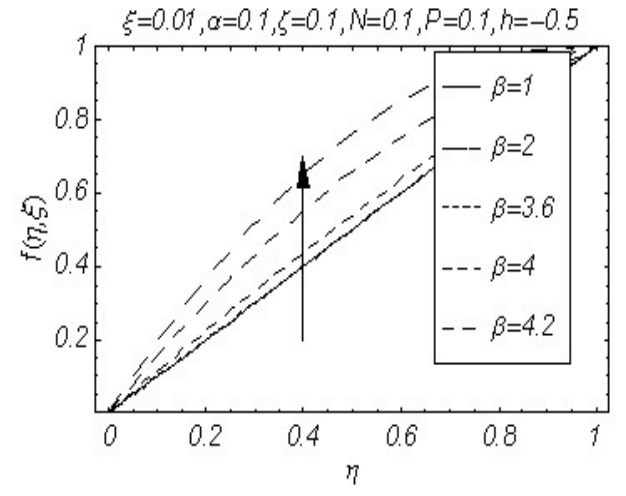

Fig. 5: Influence of $\beta$ on $\mathrm{f}(\eta, \xi)$.

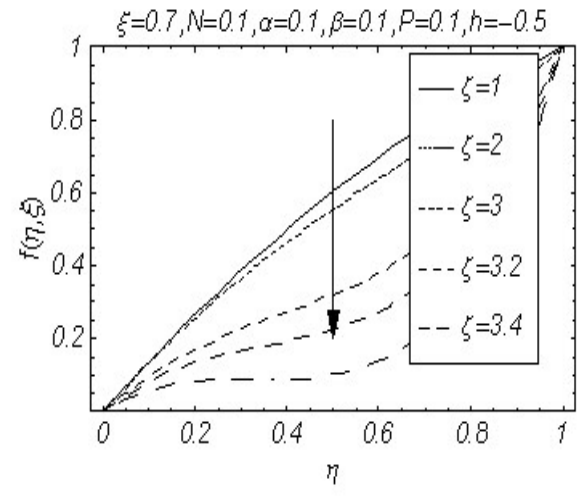

Fig. 6: Influence of $\zeta$ on $f(\eta, \xi)$. 


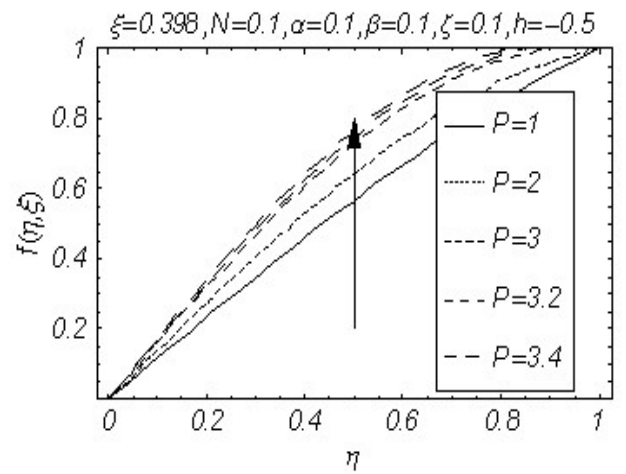

Fig. 7: Influence of $P$ on $f(\eta, \zeta)$.

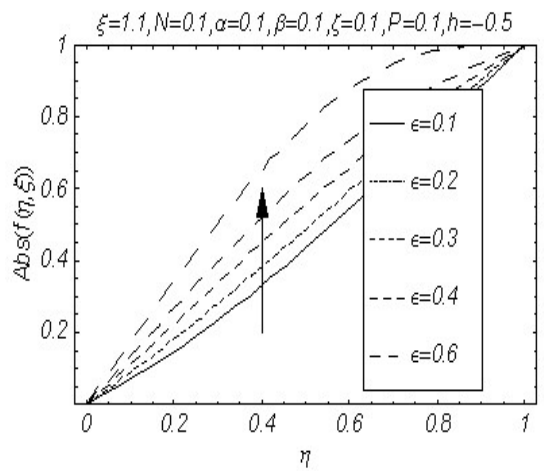

Fig. 8: Influence of $\varepsilon$ on $\operatorname{Abs}\{f(\eta, \xi)\}$.

Figure 7 depicts the variation of the pressure number on the velocity. It is observed that the velocity increases with an increase in $P$, which is consistent with what is expected. Due to the Hall current velocity field becoming complex, the absolute value of the velocity profile is plotted in Fig. 8. It is observed that with an increase in the Hall parameter $\varepsilon$, the absolute value of the velocity increases and boundary layer thickness decreases.

It is observed from Table 1 that for fixed values of $\alpha, \beta, \zeta, \hbar, P$ and $\varepsilon$ with increase in Hartmann number $N$, the absolute value of the skin friction co-efficient $R_{e} \times C f$ given in equation (16) increases for all values of the time $\xi$. Also with an increase in the Hall current $\varepsilon$, the absolute value of the skin friction co-efficient decreases for all values of the time $\xi$. For fixed values of $N, \hbar, \alpha, \beta, \zeta, P$ and $\varepsilon$ with increase in dimensionless time $\xi$ the absolute value of the skin friction co-efficient decreases at all points. Table 2 displays the variation of the skin friction co-efficient with the pressure number $P$. It is observed from Table 2 that increase in the pressure leads to an increase in the shear stress at the wall at all points which is consistent with our expectation.

Table 1: Absolute values of the skin friction co-efficient $R_{\boldsymbol{e}} \times C_{f}$ with

$$
\alpha=0.1, \beta=0.1, \zeta=0.1, P=0.1, \hbar=0.5 \text {. }
$$

\begin{tabular}{ccccccc}
\hline $\boldsymbol{\xi}$ & $\boldsymbol{\varepsilon}=\mathbf{0 . 1}$ & $\boldsymbol{\varepsilon}=\mathbf{0 . 1}$ & $\boldsymbol{\varepsilon}=\mathbf{0 . 1}$ & $\mathbf{N}=\mathbf{0 . 1}$ & $\mathbf{N}=\mathbf{0 . 1}$ & $\mathbf{N}=\mathbf{0 . 1}$ \\
& $\mathbf{N}=\mathbf{0 . 1}$ & $\mathbf{N}=\mathbf{0 . 3}$ & $\mathbf{N}=\mathbf{0 . 5}$ & $\boldsymbol{\varepsilon}=\mathbf{0 . 2}$ & $\boldsymbol{\varepsilon}=\mathbf{0 . 3}$ & $\boldsymbol{\varepsilon}=\mathbf{0 . 5}$ \\
\hline $\mathbf{0 . 2}$ & 1.98649 & 1.99305 & 1.99961 & 1.98639 & 1.98625 & 1.98586 \\
$\mathbf{0 . 4}$ & 1.89823 & 1.92579 & 1.95333 & 1.89783 & 1.89722 & 1.89559 \\
$\mathbf{0 . 6}$ & 1.80866 & 1.87047 & 1.93679 & 1.80777 & 1.80641 & 1.80276 \\
$\mathbf{0 . 8}$ & 1.74278 & 1.84279 & 1.93615 & 1.74147 & 1.73924 & 1.73350 \\
$\mathbf{1}$ & 1.74219 & 1.84016 & 1.93205 & 1.74139 & 1.73920 & 1.73325 \\
\hline
\end{tabular}

Table 2: Absolute values of the skin friction co-efficient $R_{e} \times C f$ with

$$
\alpha=0.1, \beta=0.1, \zeta=0.1, \xi=0.1, \hbar=0.5 \text {. }
$$

\begin{tabular}{ccccccc}
\hline \multirow{2}{*}{$\mathbf{P}$} & $\boldsymbol{\varepsilon}=\mathbf{0 . 1}$ & $\boldsymbol{\varepsilon}=\mathbf{0 . 1}$ & $\boldsymbol{\varepsilon}=\mathbf{0 . 1}$ & $\mathbf{N}=\mathbf{0 . 1}$ & $\mathbf{N}=\mathbf{0 . 1}$ & $\mathbf{N}=\mathbf{0 . 1}$ \\
& $\mathbf{N}=\mathbf{0 . 1}$ & $\mathbf{N}=\mathbf{0 . 3}$ & $\mathbf{N}=\mathbf{0 . 5}$ & $\boldsymbol{\varepsilon}=\mathbf{0 . 2}$ & $\boldsymbol{\varepsilon}=\mathbf{0 . 3}$ & $\boldsymbol{\varepsilon}=\mathbf{0 . 5}$ \\
\hline $\mathbf{0 . 2}$ & 2.02849 & 2.03009 & 2.03168 & 2.02847 & 2.02844 & 2.02834 \\
$\mathbf{0 . 4}$ & 2.03078 & 2.03237 & 2.03396 & 2.03076 & 2.03072 & 2.03063 \\
$\mathbf{0 . 6}$ & 2.03306 & 2.03465 & 2.03624 & 2.03304 & 2.03300 & 2.03291 \\
$\mathbf{0 . 8}$ & 2.03535 & 2.03694 & 2.03853 & 2.03532 & 2.03529 & 2.03519 \\
$\mathbf{1 . 0}$ & 2.03763 & 2.03922 & 2.04081 & 2.03761 & 2.03757 & 2.03748 \\
\hline
\end{tabular}




\section{CONCLUSION}

The Couette flow between two parallel plates filled with MHD unsteady third-grade fluid is studied analytically. The effects of the pressure and Hall current are also incorporated. A non-linear third-grade model for the fluid is used. The model is invoked into the governing equations and the resulting one dimensional equation for unsteady MHD flow is derived. This equation is solved by HAM in general to study the sensitivity of the flow to the parameters that are used in the third-grade model. The various dimensionless parameters seem to affect the velocity a lot. The velocity profile and local skin friction co-efficient are greatly influenced by the Hall parameter, pressure and Hartmann numbers.

\section{REFERENCES}

[1] Schlichting H. (1968) Boundary Layer Theory, Sixth ed., McGraw-Hill, New York.

[2] White FM. (1991) Viscous Fluid Flow, McGraw-Hill, New York, U.S.A.

[3] Bhaskara R, Bathaiah ND. (1982) Hall effects on MHD Couette flow through a porous straight channel. Def. Sci. J. 32:313-326.

[4] Ganapathy R. (1994) A note on oscillatory Couette flow in a rotating system. ASME J. Appl. Mech. 61:208.

[5] Erdogan ME. (2002) On the unsteady unidirectional flows generated by impulsive motion of a boundary or sudden application of a pressure gradient. Int. J. Non-Linear Mech. 37:1091-1106.

[6] Khaled ARA, Vafai K. (2004) The effect of the slip condition on Stokes and Couette flows due to an oscillating wall: exact solutions. Int. J. Non-Linear Mech. 39:795-809.

[7] Hayat T, Khan M, Ayub M, Siddiqui AM. (2005) The unsteady Couette flow of a second grade fluid in a layer of porous medium. Arch. Mech. 57(5):405-416.

[8] Singh KD, Gorla MG, Raj H. (2005) A periodic solution of oscillatory Couette flow through porous medium in rotating system. Indian J. Pure Appl. Math. 36:151-159.

[9] Guria M, Jana RN, Ghosh SK. (2006) Unsteady Couette flow in a rotating system. Int. J. Non-Linear Mech. 41:838-843.

[10] Hayat T, Kara AH. (2006) Couette flow of a third-grade fluid with variable magnetic field. Math. Comp. Modelling. 43:132-137.

[11] Hayat T, Momoniat E, Mahomed FM. (2008) Axial Couette flow of an electrically conducting fluid in an annulus. Int. J. Modern Phys. B 22:2489-2500.

[12] Das S, Maji SL, Guria M, Jana RN. (2009) Unsteady MHD Couette flow in a rotating system. Math. Comp. Modelling. 50:1211-1217.

[13] Zaman H, Shah MA, Ibrahim M. (2013) Unsteady incompressible Couette flow problem for the Eyring-Powell model with porous walls. Amer. J. of Comput. Math 3:313-325.

[14] Sato H. (1961) The Hall effects in the viscous flow of ionized gas between parallel plates under transverse magnetic field. J. Phys. Soc. Japan 16:1427-1433.

[15] Katagiri M. (1969) The effect of Hall currents on the magnetohydrodynamic boundary layer flow past a semi-infinite flat plate. J. Phys. Soc. Japan 27:1051-1059.

[16] Pop I, Soundalgekar VM. (1974) Effects of Hall current on hydromagnetic flow near a porous plate. Acta Mech. 20:315-318.

[17] Gupta AS. (1975) Hydromagnetic flow past a porous flat plate with Hall effects. Acta Mech. 22:281-287.

[18] Debnath L, Ray SC, Chatterjee AK. (1979) Effects of Hall current on unsteady hydromagnetic flow past a porous plate in a rotating fluid system. Z. Angew. Math. Mech. 59:469471.

[19] Khan M, Asghar S, Hayat T. (2009) Hall effect on the pipe flow of a Burgers' fluid: An exact solution. Nonlinear Analysis: Real World Applications 10:974-979. 
[20] Hayat T, Zaman H, Ayub M. (2010) Analytic solution of hydromagnetic flow with Hall effect over a surface stretching with a power law velocity. Numerical Methods for Partial Differential Equations 27(4):937-959.

[21] Ahmad M, Zaman H, Rehman N. (2010) Effects of Hall current on unsteady MHD flows of a second grade fluid. Cent. Eur. J. Phys. 8(3):422-431.

[22] Ayub M, Zaman H, Ahmad M. (2010) Series solution of hydromagnetic flow and heat transfer with Hall effect in a second grade fluid over a stretching sheet. Cent. Eur. J. Phys. 8(1):135-149.

[23] Zaman H. (2013) Hall effects on the unsteady incompressible MHD fluid flow with slip conditions and porous walls. Applied Mathematics and Physics 1(2):31-38.

[24] Liao SJ. (2003) Beyond Perturbation: Introduction to Homotopy Analysis Method, Chapman and Hall, CRC Press, Florida.

[25] Liao SJ. (1992) The proposed homotopy analysis technique for the solution of nonlinear problem. Ph.D. Thesis. Shanghai Jiao Tong University.

[26] Liao SJ. (2012) Homotopy Analysis Method in Nonlinear Differential Equations, Higher Education Press, Beijing, Springer-Verlag Berlin Heidelberg.

[27] Liao SJ. (2013) Advances in the Homotopy Analysis Method, World Scientific Publishing Company, ISBN : 978-981-4551-24-3.

[28] Liao SJ. (2009) Notes on the homotopy analysis method: Some definitions and theorems. Comm. Non-linear Sci. Numer. Simm. 14(4):983-997.

[29] Ayub M, Zaman H, Sajid M, Hayat T. (2008) Analytical solution of stagnation-point flow of a viscoelastic fluid towards a stretching surface. Comm. Nonlinear Sci. and Numer. Simul. 13:1822-1835.

[30] Zaman H, Ayub M. (2010) Series solution of unsteady free convection flow with mass transfer along an accelerated vertical porous plate with suction. Cent. Eur. J. Phys. 8(6):931939.

[31] Zaman H, Hayat T, Ayub M, Gorla RSR. (2011) Series solution for heat transfer from a continuous surface in a parallel free stream of viscoelastic fluid. Numerical Methods for Partial Differential Equations 27(6):1511-1524.

[32] Rivlin RS, Ericksen JL. (1955) Stress deformation relations for isotropic materials, J. Rational Mech. Anal. 4:323-425.

[33] Sutton GW, Sherman A. (1965) Engineering Magnetohydrodynamics, McGraw-Hill, New York. 